\title{
Advancing paternal age at birth is associated with poorer social functioning earlier and later in life of schizophrenia patients in a founder population
}

\author{
Rudolf Liebenberg ${ }^{a}$, Brigitte van Heerden ${ }^{a,}{ }^{*}$, René Ehlers ${ }^{b}$, Ilse Du Plessis ${ }^{a}$, J. Louw Roos ${ }^{a}$
}

\author{
${ }^{a}$ Department of Psychiatry, University of Pretoria, Weskoppies Hospital, Private Bag X113, Pretoria, Pretoria \\ 0001, South Africa \\ ${ }^{b}$ Department of Statistics, University of Pretoria, Pretoria, South Africa \\ "Corresponding author. Tel.: +27 12319 9720, brigeyvh@gmail.com
}

\section{Highlights}

- Early deviant behaviour.

- Increasing paternal age.

- Social dysfunction.

- Social dysfunction.

- Learning disabilities.

- Interpersonal relationships.

\begin{abstract}
Consistent associations have been found between advanced paternal age and an increased risk of psychiatric disorders, such as schizophrenia in their offspring. This increase appears to be linear as paternal age increases. The present study investigates the relationship between early deviant behaviour in the first 10 years of life of patients as well as longer term functional outcome and paternal age in sporadic Afrikaner founder population cases of schizophrenia. This might improve our understanding of Paternal Age-Related Schizophrenia (PARS). Follow up psychiatric diagnosis was confirmed by the Diagnostic Interview for Genetic Studies (DIGS). An early deviant childhood behaviour semi-structured questionnaire and the Specific Level of Functioning Assessment (SLOF) were completed. From the logistic regression models fitted, a significant negative relationship was found between paternal age at birth and social dysfunction as early deviant behaviour. Additionally, regression analysis revealed a significant negative relationship between paternal age at birth and the SLOF for interpersonal relationships later in life. Early social
\end{abstract}


dysfunction may represent a phenotypic trait for PARS. Further research is required to understand the relationship between early social dysfunction and deficits in interpersonal relationships later in life.

\section{Keywords}

Paternal age-related schizophrenia (PARS), early deviance, social dysfunction, functional outcome, interpersonal relationships, learning disabilities.

\section{Introduction}

Children of older fathers have an increased risk of genetic disorders. Growing evidence suggests that, independent of maternal age, the offspring of older fathers are more susceptible to a wide range of conditions (Goriely et al., 2012). Studies have shown consistent associations of advanced paternal age (APA) with an increased risk of schizophrenia in offspring (Malaspina et al., 2001) as well as a range of other psychiatric morbidities, such as autism spectrum disorders (Grether et al., 2009; Hultman et al., 2011), bipolar disorder (Frans et al., 2008), epilepsy (Vestergraad et al., 2005), obsessivecompulsive disorder (Wu et al., 2012) and reduced cognitive abilities in infancy and childhood (Saha et al., 2009). There appears to remain a notable lack of consensus on how to define what constitutes advanced paternal age itself.

Paternal age-related schizophrenia (PARS) was operationally defined by Rosenfield et al (2010) as those with no family history of schizophrenia or psychosis and whose father's age at birth was 35 years or older. They found that subjects without a family history of schizophrenia and where the fathers were 35 years or older at the patients' birth, did not show the expected sex differences consistently observed with schizophrenia patients in general. This refers to the earlier onset age and more severe negative symptoms found in males versus females. It was proposed that PARS may represent a sub-type of schizophrenia (Rosenfield et al., 2010).

The literature suggests that for many disorders there is no obvious cut-off point beyond which paternal age should be considered "advanced". Rather, there appears to be a linear increase in risk of the disorder with increasing paternal age. Miller et al found a J-shaped curve for the relationship between paternal age and risk of schizophrenia. In a meta-analysis of paternal age and schizophrenia risk in male versus female offspring, it was found that there is a significant increase in risk of schizophrenia in the offspring with increasing paternal age ( $\geq 30$ years of age). It was also found that there is a significant increase in risk of schizophrenia in the offspring of younger fathers ( $<25$ years of age), which may also be associated with an increased risk in males, but not in females. The population attributable risk percentage (PAR \%) was $10 \%$ for paternal age $\geq 30$ and $5 \%$ for paternal age $<25$ in all studies. (Miller et al, 2010) 
Germ cell development differs radically between human males and females. In the female, germ cells undergo only 22 mitotic cell divisions in utero, followed by a long period of rest until puberty. In the male, by contrast, after 30 mitotic divisions during embryogenesis, spermatogenesis is reinitiated at puberty and adult spermatogonial cells undergo regular mitotic divisions to produce sperm. In a simple turnover model, this means that in a 20year-old man, the spermatogonial cells have undergone approximately 150 cell divisions. By the age of 50 years, this number has reached approximately 840 (Goriely et al., 2013). It follows that recent genomic studies have reported that the age of the fathers at conception is an important factor in determining the number of de novo mutations in their offspring (Kong et al., 2012). Accumulated mutations and chromosomal anomalies in reproductive germ cells might account for the largest part of the risk of mental disorders associated with advanced paternal age (Goriely et al., 2013). New mutations may explain why schizophrenia is maintained in the population, despite the significant reproductive disadvantages of affected individuals (Malaspina et al., 2001).

Patients with schizophrenia and their first degree relatives have impaired social functioning, hence, it follows that impaired social functioning may represent an intermediate phenotype of the illness. Research results of social functioning studies in the general population and advanced paternal age suggest that the risk pathways between advanced paternal age and schizophrenia, at least partially, include mildly deleterious effects of social functioning (Weiser et al., 2008).

Schizophrenia is seen as a disease affected by multiple genes and environmental factors, but these factors can also contribute to the manifestations of other mental disorders or intermediate phenotypes such as poor cognitive or social functioning. Deleterious effects of the risk factors are manifested as mental illness only when individuals cross a certain severity threshold (Weiser et al., 2008). Thus, advanced paternal age might not be a risk factor for a specific mental disorder such as schizophrenia, but rather increases the risk for brain malfunction that rarely crosses the threshold for a clinical diagnosis.

Against the above background the following research question was formulated: how does increasing paternal age at birth correlate with early deviant behaviour in the first ten years of life, and with the specific level of functioning in adulthood in sporadic cases with schizophrenia and schizoaffective disorder in a founder population?

\section{Methods and Materials:}

\subsection{Subject Recruitment:}

A number of families with schizophrenia have been recruited from the Afrikaner population over a number of years for a collaborative study. (Karayiorgou et al., 2004) These subjects form part of a cohort of cases enrolled in ongoing genetic research, being conducted 
collaboratively by the Department of Psychiatry, University of Pretoria and the Laboratory for Human Genetics, Columbia University, New York.

The families in this cohort are of varying structure, including both sporadic cases and multiple affected family members. Demographic data, including paternal ages of patients was available. Each subject who met the criteria for schizophrenia or schizoaffective disorder (APA, 1994) underwent a careful, in-person diagnostic evaluation using the Diagnostic Interview for Genetic Studies (DIGS) at recruitment (Nurnberger et al., 1994).

The Afrikaner population in South Africa is a genetically and environmentally homogeneous population who have descended from mostly Dutch immigrants who settled in South Africa from 1652 onwards (Karayiorgou et al., 2004). In addition to the genetic homogeneity, the Afrikaners are valuable for genetic studies because they present a close-knit family structure and offer the potential to perform detailed genealogical analysis, which affords reliable discrimination of familial and non-familial (sporadic) forms of the disease (Xu et al., 2012). We identified and extracted the sporadic cohort (i.e. no history of schizophrenia in first- or second-degree relatives) from within the original cohort. A subset of probands from this sample was re-contacted for participation in the current study by the principal clinical investigator of the collaborative study. These probands were selected dependent on the presence of a sporadic form of the disease.

\subsection{Study Design and Participants:}

This observational retrospective cohort study included 41 Afrikaner South African patients; 35 males and 6 females. Their ages at evaluation for the present study ranged from 16 to 62 years with a mean age of 37 years. Their paternal ages at birth ranged from 17 to 46 years with a mean of 28.9 years.

Preceding our interviews, subjects had each been formally diagnosed with schizophrenia or schizoaffective disorder by an experienced consultant psychiatrist using the Diagnostic and Statistical Manual of Mental Disorders, Fourth Edition (DSM-IV) at Weskoppies Psychiatric Hospital, Pretoria.

The criteria used for being classified as an Afrikaner included: Afrikaans language, typical Afrikaans surname of both parents and grandparents on the paternal and maternal side, and genealogical tracings by a genealogist (Karayiorgou et al., 2004)

\subsubsection{Stability of diagnosis}

The lifetime diagnoses originally assigned to the 41 subjects were remarkably stable across the three groups. The initial study diagnosis was made by a best-estimate process using medical records and collateral information. The diagnoses remained the same in all but four cases. The stability of diagnoses was confirmed by the re-administration of the DIGS and 
collecting other relevant data. The absence of a positive family history was also confirmed at re-evaluation, therefore confirming the sporadic nature of the illness.

One patient had a dual diagnosis of Asperger Syndrome and schizophrenia at initial assessment. After follow up assessment the diagnosis of Asperger Syndrome was discarded. The modification of diagnosis from schizophrenia to schizoaffective disorder in three patients was done because the longitudinal course of the illness was taken into account and a more accurate picture of the mood symptoms was available at the follow up evaluation. The reliability coefficients for schizoaffective disorder are lower than for other diagnoses made in the DIGS (Nurnberger et al., 1994). It remains difficult to assess reliably the mood syndrome criteria in the DSM IV of schizoaffective disorder.

No major categorical diagnostic changes were made and in all 41 patients psychosis remained central to their clinical presentation, supporting the reliability of the final bestestimate process initially employed in making a lifetime diagnosis.

\subsection{Variables Examined:}

Our study consisted of confirmation of the patient's psychiatric diagnosis, based on a followup psychiatric interview using the DIGS (Nurnberger et al., 1994). The interviews were administered by two investigators training in psychiatry and were overseen by the principal investigator (a consultant psychiatrist), as well as a second consultant psychiatrist. The final psychiatric diagnosis represented a consensus amongst the research clinicians. Follow-up interviews were not performed blind and reports from the initial interviews were available to investigators as information regarding the longitudinal course of the illness is crucial in the final diagnostic formulation.

All participants were also interviewed using a semi-structured questionnaire probing for early deviant childhood behaviour in the first 10 years of life. (Appendix A) Age 10 was used as a cut-off in order to exclude behaviours that might be attributable to pre-pubertal hormonal changes. The early deviant behaviour questionnaire probed seven areas of possible deviance, including social dysfunction (avoidance of other children, inability to have friends, isolated play), extreme odd behaviours (unprovoked screaming fits, disorganised or irrational behaviour, inappropriate affect), unprovoked aggression, extreme anxiety, chronic sadness, attention impairment and learning disabilities (Sobin et al., 2003). Yes/no responses were recorded for each item. Behaviours were considered present only if the behaviour was both of a more permanent nature and severe. If an environmental precipitant or other social circumstance could explain the deviant behaviour it was coded as absent. Learning disabilities and/or attention impairment were considered present only if the child had received a formal diagnosis or if these were reported by teachers or noted in school reports (Scholtz et al., 2005). Additional information was obtained by accompanying parents or social workers and interviewers were therefore not blinded to paternal age. 
The early non-psychotic childhood deviance questionnaire has been used in several studies in the Afrikaner founder population and its use was also compared to a USA genetic sample (Sobin et al., 2001; Sobin et al., 2003; Scholtz et al., 2005; Roos et al., 2006). Early nonpsychotic childhood deviance in the Afrikaner population distinguished a distinct subtype of patients and forms of early deviance manifested were meaningfully linked to disease outcome (Sobin et al., 2003). In a study by Liu et al (2002) the families were stratified by history or early deviant behaviour. The initial molecular findings at the 22q11 locus supported a genetic basis for early deviant behaviour.

Schneider's Specific Level of Functioning Assessment (SLOF) is commonly used to assess functioning in patients with schizophrenia (Bowie et al., 2008). The SLOF was administered to and completed by the patient's caseworker or caregiver to ensure relative objectivity. The SLOF is a 43-item multidimensional behavioural survey and assesses the patient's current functioning and behaviour across six domains: (1) physical functioning, (2) personal care skills, (3) interpersonal relationships, (4) social acceptability, (5) activities of community living, and (6) work skills. Each of the 43 questions is rated on a five-point Likert scale, rendering both a score for each of the six areas, as well as an overall final score. Total possible scores range from 43 to 215 . The higher the total score, the better the overall functioning of the patient (Schneider et al., 1983). The SLOF scale was the best-rated scale by the Validation of Everyday Real World Outcomes (VALERO) study (Harvey et al., 2011) and has excellent reliability and validity. (Schneider et al., 1983)

\subsection{Ethical Considerations:}

The selected subjects were contacted again by the principal investigator of the initial study, who explained the purpose of the present study, as well as an outline of the interview and questionnaires that were to be conducted and completed, respectively. Preceding the follow-up interview, informed consent was obtained again in order to preserve the autonomy and self-determination of each of the research subjects.

Ethical approval of this study was obtained from the Ethics Committee of the Faculty of Health Sciences at the University of Pretoria. (Ethics reference no. 61+62/2014)

\subsection{Data Analysis:}

Data was entered into Excel and analysed with SAS 9.2 software. Logistic regression models were fitted to investigate the relationship between paternal age at birth and the presence or absence of each of the seven different early deviant behaviours in the first ten years of life. Linear regression models were also fitted with paternal age at birth as the independent variable and different SLOF scores as the dependent variable. 


\section{Results}

The sample included a total of 41 patients with a lifetime history of either schizophrenia or schizoaffective disorder, of which 35 were male. These patients had no known family history of such disorders and were therefore classified as sporadic cases.

\subsection{Early deviant behaviours in the first ten years of life}

The relationship between paternal age at birth of the patient and the presence or absence of the various early deviant behaviours in the first ten years of life was studied by fitting logistic regression models. Only the model with social dysfunction as dependent variable was significant (Wald chi-square $p$-value $=0.0131$ ). The mean paternal age at birth of patients displaying social dysfunction is 33.1 compared to the mean paternal age at birth of 26.4 for patients not displaying this behaviour. The point estimate of the odds ratio is 1.147, indicating that for a one year increase in paternal age at birth, the odds of the presence of social dysfunction as early deviant behaviour increases by $14.7 \%$. The $95 \%$ Wald confidence interval for this point estimate is $(1.029 ; 1.279)$.

Summary statistics for the early deviant behaviours are given in Table 1 . It shows the percentage of patients $(n=41)$ displaying a specific early deviant behaviour as well as the means of the paternal age at birth for patients when the deviant behaviour is absent and when it is present. The $p$-values for the Wald chi-square statistic from the logistic regression models are also given.

\begin{tabular}{|c|c|c|c|c|c|c|}
\hline & \multirow[t]{2}{*}{$\begin{array}{l}\text { Patients with } \\
\text { early deviant } \\
\text { behaviour (\%) }\end{array}$} & \multicolumn{2}{|c|}{$\begin{array}{l}\text { Paternal age when } \\
\text { deviant behaviour } \\
\text { is absent }\end{array}$} & \multicolumn{2}{|c|}{$\begin{array}{l}\text { Paternal age when } \\
\text { deviant behaviour } \\
\text { is present }\end{array}$} & \multirow[t]{2}{*}{$\begin{array}{l}\text { p-value for Wald } \\
\text { chi-square }\end{array}$} \\
\hline & & Mean & $\pm S D$ & Mean & $\pm S D$ & \\
\hline $\begin{array}{l}\text { Social } \\
\text { Dysfunction }\end{array}$ & 65.9 & 26.4 & 5.2 & 33.1 & 7.8 & 0.0131 \\
\hline $\begin{array}{l}\text { Extreme odd } \\
\text { behaviours }\end{array}$ & 9.8 & 30.6 & 7.7 & 32.3 & 7.9 & 0.6878 \\
\hline $\begin{array}{l}\text { Unprovoked } \\
\text { Aggression }\end{array}$ & 9.8 & 31.1 & 7.7 & 28.5 & 8.1 & 0.5243 \\
\hline $\begin{array}{l}\text { Extreme } \\
\text { Anxiety }\end{array}$ & 14.6 & 31.0 & 7.7 & 29.5 & 7.7 & 0.6477 \\
\hline $\begin{array}{l}\text { Chronic } \\
\text { Sadness }\end{array}$ & 31.7 & 30.1 & 7.6 & 32.2 & 7.8 & 0.4125 \\
\hline $\begin{array}{l}\text { Attentional } \\
\text { Impairment }\end{array}$ & 63.4 & 29.5 & 7.5 & 31.6 & 7.8 & 0.3913 \\
\hline $\begin{array}{l}\text { Learning } \\
\text { Disability }\end{array}$ & 41.5 & 28.9 & 7.4 & 33.5 & 7.3 & 0.0595 \\
\hline
\end{tabular}

Table 1: Summary statistics for paternal ages at birth for various early deviant behaviours 


\subsection{Specific level of functioning assessment (SLOF)}

Regression models were fitted with paternal age at birth as the independent variable and each of the six different SLOF scores as dependent variables, including physical functioning, personal care skills, interpersonal relationships, social acceptability, activities of community living and work skills. Only the model with the SLOF scores for interpersonal relationships as dependent variable was significant ( $p$-value=0.0067). The residuals of the model did not deviate significantly from a normal distribution ( $p$-value $=0.1644$ for Shapiro-Wilk test for normality). Residual plots also confirmed the assumptions of constant variance and linearity. The point estimate of the slope is -0.349 which indicates that for a one year increase in paternal age at birth, the average SLOF score for interpersonal relationships decreases with 0.349 units. The $95 \%$ confidence interval for the point estimate of the slope is $(-0.595$; 0.102). The correlation coefficient between paternal age at birth and the SLOF score for interpersonal relationships is $-0.4168\left(R^{2}=0.1737\right)$. Although this is low, it is still significant on the $5 \%$ level. A scatter plot of SLOF score for interpersonal relationships against paternal age at birth is given in the graph below.

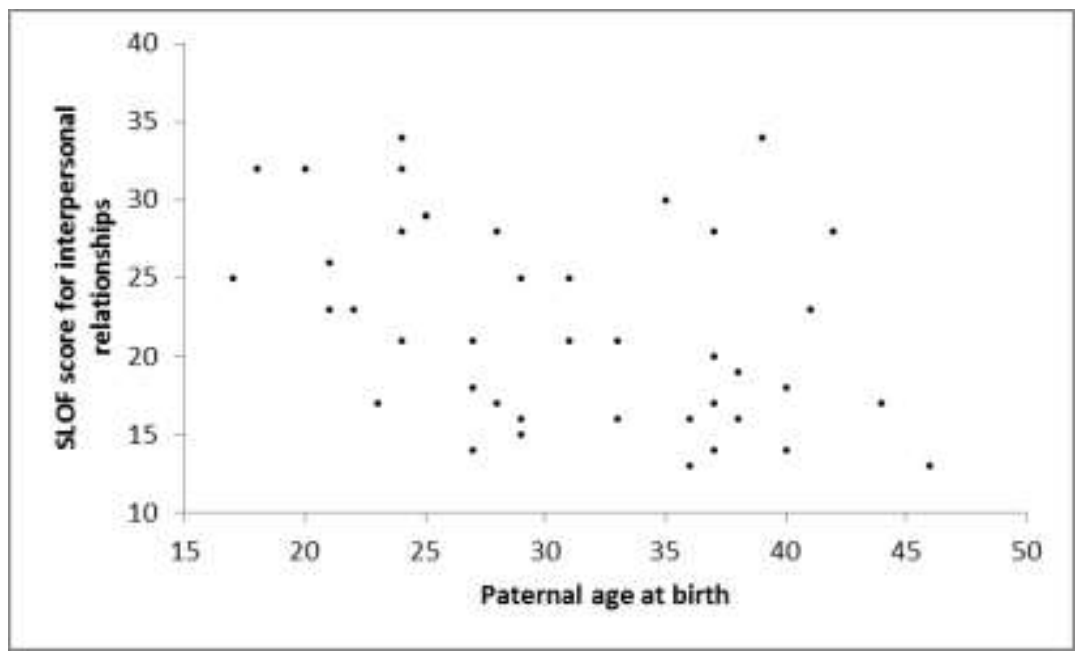

Graph 1: Scatter plot for paternal age at birth and SLOF score for interpersonal relationships

\subsection{Stability of diagnosis}

The lifetime diagnoses originally assigned to the 41 subjects were remarkably stable across the three groups. The initial study diagnosis was made by a best-estimate process using medical records and collateral information. The diagnoses remained the same in all but four cases. The stability of diagnoses was confirmed by the re-administration of the DIGS and collecting other relevant data. The absence of a positive family history was also confirmed at re-evaluation, therefore confirming the sporadic nature of the illness.

One patient had a dual diagnosis of Asperger Syndrome and schizophrenia at initial assessment. After follow up assessment the diagnosis of Asperger Syndrome was discarded. The modification of diagnosis from schizophrenia to schizoaffective disorder in three patients was done because the longitudinal course of the illness was taken into account and a more accurate picture of the mood symptoms was available at the follow up evaluation. 
The reliability coefficients for schizoaffective disorder are lower than for other diagnoses made in the DIGS (Nurnberger et al., 1994). It remains difficult to assess reliably the mood syndrome criteria in the DSM IV of schizoaffective disorder.

No major categorical diagnostic changes were made and in all 41 patients psychosis remained central to their clinical presentation, supporting the reliability of the final bestestimate process initially employed in making a lifetime diagnosis.

\section{Discussion:}

An outstanding finding in the investigation of the relationship between paternal age at birth of schizophrenia participants and early deviant behaviours in the first 10 years of life was in the domain of social dysfunction. The $p$-value for the Wald Chi-square statistic in the logistic regression model was significant on a $5 \%$ level for social dysfunction. For every year increase in the paternal age at birth, the odds of displaying social dysfunctions in the first 10 years of life increased by $14.7 \%$. This would fit in with a linear increase in risk of the disorder with increasing paternal age as reported by Miller in 2010. This suggests that mildly deleterious social functioning in the patient's first 10 years of life may make out part of the risk pathways between advanced paternal age and schizophrenia.

Successful social interactions involve interpersonal sensitivity, or sensitivity to the feeling, affect and behaviours of others as well as the ability to convey and communicate cues to elicit desired response from others. Both the ability to judge and be judged accurately serve adaptive functions in social interactions (Ambady et al., 1995). Thus, it is plausible that a disruption in any part of this process (either sensitivity to or judgements about others, or being judged accurately by others) will affect social interactions and functioning. This may lead other children not to engage in play with these individuals, or conversely, these patients may find such social interactions stressful and may keep to themselves, as was reported on the first question in the early non-psychotic deviant behaviour questionnaire.

Although impaired social functioning is evident in patients with older fathers prior to the psychosis onset stage of schizophrenia, we know little about the processes underlying the emergence of social functioning impairment itself premorbidly and later, during the development of the clinical disorder. Whether deficits in interpersonal sensitivity lead to, augment, or maintain social functioning deficits in individuals with schizophrenia, remains opaque (Miller and Lenzenwerger, 2012). In a paper by the same authors on schizotypy, social cognition and interpersonal sensitivity, the researchers examined interpersonal sensitivity in schizotypes and shed light on the social functioning problems seen in patients with schizophrenia in a translational research framework. The authors suggest that the relative specificity of these deficits in the schizotypy group may mark a first step in 
identifying a class of interpersonal sensitivity deficits that could serve as potential endophenotypes for schizophrenia.

Where does social functioning fit in with the social cognition construct in schizophrenia? Social cognition refers broadly to a research domain examining those processes underlying social functioning, specifically those cognitive processes involved in perceiving and interpreting interpersonal relevant information (Ostrom, 1984). Adolescents genetically atrisk for schizophrenia showed social skills impairments, but these impairments were unrelated to the theory of mind related social cognition constructs as reported by Gibson et al. in 2010.

Recent meta-analyses have indicated that social cognitive function in patients with schizophrenia was markedly impaired (Savla et al., 2013; Chung et al., 2014). Deficits in social cognition are associated with functional outcome of schizophrenia and contribute to the functional outcome beyond neurocognition (Schmidt et al., 2011; Mehta et al. 2013). Social cognitive deficits are relatively stable throughout the disease course (Addington et al., 2006; Horan et al., 2012) given that these deficits are observed during remission (Sprong et al., 2007; Mehta et al., 2013b), as well as in relatives (Lavoie et al., 2013). These findings suggest that social cognitive deficits represent a trait marker for schizophrenia that is related to a genetic aspect. Some inconsistencies still exist within each domain of social cognition and would require further research. (Fitzdon and Reddy, 2012; Pinkham, 2014). The fact that learning disability was also affected in the early years of these patients would fit in with a neurodevelopmental disorder paradigm of schizophrenia.

Multiple studies have demonstrated that individuals who do better on tasks of interpersonal sensitivity are more interpersonally skilled and are better adjusted than people who do poorly (Ambady et al., 2001). Those who perform poorly on tasks of interpersonal sensitivity have known interpersonal and social functioning deficits (Toomey et al., 2002). In this study, the Specific Level of Functioning Assessment (SLOF) evaluated the patient's current functioning and behaviour across six domains. There was a significant negative linear relationship ( $p$-value $=0.0067$ ) between the SLOF score for interpersonal relationships and paternal age at birth. On the other hand, in the present study the relationship between SLOF score for social acceptability and paternal age was not statistically significant ( $p$ value $=0.9093$ ). With the above findings of interpersonal relationships, one would have expected similar results for social acceptability. One may postulate that the scoring of social acceptability by caregivers may have been influenced by the fact that they are used to interacting with these patients, and may find them socially acceptable. This may be not the case when answered by other non-caregiver individuals.

The question remains as to whether the social dysfunction early in the lives of paternal age related schizophrenia patients can be seen as a phenotypic trait in this group. Further 
research is also needed to understand how social dysfunction early in the lives of these patients corresponds with interpersonal relationship problems after the onset of the psychosis stage of this neurodevelopmental disorder.

\section{Limitations of study}

Sample sizes were small and, due to the long-term follow-up nature of this research, a larger sample size could not be obtained, especially in certain paternal age groups. The allocation of a timeline also influenced the period for completion of the research. Larger sample sizes for future studies would be of interest. We also recognise the importance of significant findings in small study groups and would like to see this research contribute to evidencebased medicine as part of future collaborations and/or meta-analyses (Haidich, 2010).

Information regarding early deviant behaviours involved retrospective reporting and was mostly obtained from the patients themselves. While the validity of this method may be questioned, it is possible that respondents minimised or downplayed the extent of their deviant behaviours, with this potential bias strengthening our findings.

\section{Funding}

This research project was funded by the University of Pretoria as well as the NRF Incentive Funding for Rated Researchers. The authors have no conflicts of interest to report.

\section{Acknowledgements}

The authors would like to thank YANA home for persons suffering from schizophrenia and their social worker, Amelda Swan, for their invaluable help in recruiting appropriate patients, obtaining collateral information and providing a space to conduct lengthy interviews. The authors also extend special thanks to the families for their ongoing participation in our work.

\section{Conflict of interest}

The authors do not have any actual or potential conflict of interest to disclose

\section{Contributors}

JLR, WFRL, BLVH designed the study and wrote the protocol.

WFRL, BLVH performed the literature search and collected the data 
JLR, WFRL, BLVH performed the analysis

RE undertook the statistical analysis.

$J L R$, WFRL, BLVH wrote the first draft of the manuscript

All authors contributed to and have approved the final manuscript

\section{References:}

Addington, J., Saeedi, H., Addington, D., 2006. Influence of social perception and social knowledge on cognitive and social functioning in early psychosis. British Journal of Psychiatry 189, 373-378.

Ambady, N., Halloahan, M., Rosenthal R., 1995. On judging and being judged accurately in zero acquaintance situations. Journal of Personality and Social Psychology 77, 538-547.

Ambady, N., La Plante, D., Johnson E., 2001. The slice judgement as a measure of interpersonal sensitivity. In: Hall, J.A., Bernieri, F.J. (Eds). Interpersonal sensitivity: Theory and measurement. Mahwah, Erlbaum, pp. $89-101$.

American Psychiatric Association, 1994. Diagnostic and statistical manual of mental disorders: DSMIV (4th ed). Washington, DC: American Psychiatric Association.

Bowie, C.R., Leung W.W., Reichenberg, A., et al., 2008. Predicting schizophrenia patients' real-world behaviour with specific neuropsychological and functional capacity measures. Biological Psychiatry 63, 505-511.

Chung, Y.S., Barch, D., Strube, M., 2014. A meta-analysis of mentalizing impairments in adults with schizophrenia and autism-spectrum disorder. Schizophrenia Bulletin 40, 602-616.

Fiszdon, J.M., Reddy, L.F., 2012. Review of social cognitive treatments for psychosis. Clinical Psychological Review 32(8), 724-740.

Frans, E.M., Sandin, S., Reichenberg, A., Lichtenstein, P., Lângström, N., Hultman, C.M., 2008. Advancing paternal age and bipolar disorder. Archives of General Psychiatry 65, 1034-1040.

Gibson, C.M., Penn, D.L., Prinstein, M.J., Perkins, D.O., Belger, A, 2010. Social skill and social cognition in adolescents at genetic risk for psychosis. Schizophrenia Research 122, 179-184.

Goriely, A., Wilkie, A.O.M., 2012. Paternal age effect mutations and selfish spermatogonial selection: Causes and consequences for human disease. The American Journal of Human Genetics 90, 125-200.

Goriely, A., McGrath, J., Hultman, C.M., Wilkie, A., Malaspina, D., 2013. "Selfish spermatogonial selection": a novel mechanism for the association between advanced paternal age and neurodevelopmental disorders. American Journal of Psychiatry 170, 599-608. 
Grether, J.K., Anderson, M.C., Croen, L.A., Smith, D., Windham, G.C., 2009. Risk of autism and increasing maternal and paternal age in a large north American population. American Journal of Epidemiology 170, 1118-1126.

Haidich, A.B., 2010. Meta analysis in medical research. Hippokratia 14 (S1), S29-S37.

Harvey, P.D., Raykov, T., Twamley, E.W., Vella, L., Heaton, R.K., Patterson, T.L., 2011. Validating the measurement of real-world functional outcomes: phase I results of the VALERO study. American Journal of Psychiatry 168, 1195-1201.

Horan, W.P., Green, M.F., DeGroot, M., Fiske, A., Hellemann, G., Kee, K., Kern, R.S., Lee, J., Sergi, M.J., Subotnik, K.L., Sugar, C.A., Ventura, J., Nuechterlein, K.H., 2012. Social cognition in schizophrenia, part 2: 12-month stability and prediction of functional outcome in first-episode patients. Schizophrenia Bulletin 38, 865-872.

Hultman, C.M., Sandin, S., Levine, S.Z., Lichtenstein, P., Reichenberg, A., 2011. Advancing paternal age and risk of autism: new evidence from a population-based study and a meta-analysis of epidemiological studies. Molecular Psychiatry 16(12), 1203-1212.

Jaffe, A.E., Eaton, W.W., Straub, R.E., Marenco, S., 2014. Paternal age, de novo mutations and schizophrenia. Molecular Psychiatry 19, 274-283.

Karayiorgou, M., Rottington, M., Abecasis, G.R., Pretorius, H.W., Robertson, B., Kaliski, S., Lay, S., Sobin, C., Moller, N., Lundy, L.S., Blundell, M.L., Gogos, J.A., Roos, J.L., 2004. Phenotypic characterization and genealogical tracing in an Afrikaner schizophrenia database. American Journal of Medical Genetics Part B: Neuropsychiatric Genetics 124B, 20-28.

Kong, A., Frigge, M.L., Masson, G., Besenbacher, S., Sulem, P., Magnusson, G., Gudjonsson, S.A., Sigurdsson, A., Jonasdottir, A., Jonasdottir, A., Wong, W.S., Sigurdsson, G., Walters, G.B., Steinberg, S., Helgason, H., Thorleifsson, G., Gudbjartsson, D.F., Helgason, A., Magnusson, O.T., Thorsteinsdottir, U., Stefansson, K. Rate of de novo mutations and the importance of father's age to disease risk. Nature 488, 471-575.

Lavoie, M.-A.A., Plana, I., Bédard Lacroix, J., Godmaire-Duhaime, F., Jackson, P.L., Achim, A.M., 2013. Social cognition in first-degree relatives of people with schizophrenia: a meta-analysis. Psychiatry Research 209, 129-135.

Liu, H., Heath, S.C., Sobin, C., Roos, J.L., Galke, B.L., Blundell, M.L., Lehane, M., Robertson, B., Wijsman, E.M., Rapoport, J.L., Gogos, J.A., Karayiorgou, M., 2002. Genetic variation at the 22q11 PRODH2/DGCR6 locus presents an unusual pattern and increases susceptibility to schizophrenia. Proceedings of the National Academy of Sciences of the United States of America 99(6), 3717-3722.

Malaspina, D., Harlap, S., Fennig, S., Helman, D., Nahon, D., Feldman, D., Susser, E.S., 2001. Advancing paternal age and the risk of schizophrenia. Archives of General Psychiatry 58, 361-367.

Malaspina, D., Corcoran, C., Fahim, C., Berman, A., Harkavy-Friedman, J., Yale, S., Goetz, D., Harlap, S., Gorman, J., 2002. Paternal age and sporadic schizophrenia: evidence for de novo mutations. American Journal of Medical Genetics Part B: Neuropsychiatric genetics 114, 299-303. 
Mehta, U.M., Thirtalli, J., Subbakrishna, D.K., Gangadhar, B.N., Eack, S.M., Keshavan, M.S., 2013a. Social and neuro-cognition as distinct cognitive factors in schizophrenia: a systematic review. Schizophrenia Research 148, 3-11.

Mehta, U.M., Thirtalli, J., Naveen Kumar, C., Keshav Kumar, J., Keshavan, M.S., Gangadhar, B.N., 2013b. Schizophrenia patients experience substantial social cognition deficits across multiple domains in remission. Asian Journal of Psychiatry 6, 324-329.

Miller, B., Messias, E., Miettunen, J., Alaräisänen, A., Järvelin, M.R., Koponen, H., Räsänen, P., Isohanni, M., Kirkpatrick, B., 2010. Meta-analysis of paternal age and schizophrenia risk in male versus female offspring. Schizophrenia Bulletin 37, 1039-1047.

Miller, B., Lenzenwerger, M.F., 2012. Schizotypy, social cognition and interpersonal sensitivity. Personality Disorders: Theory, Research and Treatment 3, 379-392.

Nurnberger, J.I. Jr, Blehar, M.C., Kaufmann C.A., York-Cooler, C., Simpson, S.G., Harkavy-Friedman, J., Severe, J.B., Malaspina, D., Reich, T., 1994. Diagnostic interview for genetic studies: rationale, unique features, and training. NIMH Genetics Initiative. Archives of General Psychiatry 51, 849-859.

Ostrom, T., 1984. The sovereignty of social cognition. In: Wyer, R., Srull, T. (Eds), Handbook of Social Cognition Vol 1. Hillsdale, Erlbaum, pp 1-13.

Petersen, L., Mortensen, P.B., Petersen, C.B., 2011. Paternal age at birth of first child and risk of schizophrenia. American Journal of Psychiatry 168(1), 82-88.

Pinkham, A.E., 2014. Social cognition in schizophrenia. Journal of Clinical Psychiatry 75 (Suppl. 2), 14 19.

Roos, J.L., Pretorius, H.W., Karayiorgou, M., Boraine, H., 2006. Cannabis and other variables affecting age at onset in a schizophrenia founder population. South African Psychiatry Review 9, 99103.

Rosenfield, P.J., Kleinhaus, K., Opler, M., Perrin, M., Learned, N., Goetz, R., Stanford, A., Messinger, J., Harkavy-Friedman, J., Malaspina, D., 2010. Later paternal age and sex differences in schizophrenia symptoms. Schizophrenia Research 116, 191-195.

Saha, S., Barnett, A.G., Foldi, C., Burne, T.H., Eyles, D.W., Buka, S.L., McGrath, J.J., 2009. Advanced paternal age is associated with impaired neurocognitive outcomes during infancy and childhood. PLOS Medicine 6: e40.

Savla, G.N., Vella, L., Armstrong, C.C., Penn, D.L., Twamley, E.W., 2013. Deficits in domains of social cognition in schizophrenia: a meta-analysis of the empirical evidence. Schizophrenia Bulletin 39, 979992.

Schmidt, S.J., Mueller, D.R., Roder, V., 2011. Social cognition as a mediator variable between neurocognition and functional outcome in schizophrenia: empirical review and new results by structural equation modeling. Schizophrenia Bulletin 37, s41-s54.

Schneider, L.C., Struening, E.L., 1983. SLOF: A behavioural rating scale for assessing the mentally ill. 
Social work research \& abstracts 19, 9-21.

Scholtz, M.C., Janse van Rensburg, M.S., Roos, J.L., Pretorius, H.W., Karayiorgou, M., Levin, J. Early non-psychotic deviant behaviour as an endophenotypic marker in bipolar disorder, schizoaffective disorder and schizophrenia. South African Psychiatry Review 8, 153-159.

Sobin, C. Blundell, M.L., Conry, A., Weiller, F., Gavigan, C., Haiman, C., Karayiorgou, M., 2001. Early, non-psychotic deviant behaviour in schizophrenia: a possible endophenotypic marker for genetic studies. Psychiatry Research 101, 101-113.

Sobin, C., Roos, J.L., Pretorius, H.W., Lundy, L.S., Karayiorgou, M., 2003. A comparison study of early non-psychotic deviant behaviour in Afrikaner and US patients with schizophrenia or schizoaffective disorder. Psychiatry Research 117, 113-125.

Sprong, M., Schothorst, P., Vos, E., Hox, J., van Engeland, H., 2007. Theory of mind in schizophrenia: a meta-analysis. British Journal of Psychiatry 191, 5-13.

Toomey, R., Schuldberg, D., Corrigan, P., Green, M.F., 2002. Nonverbal social perception and symptomatology in schizophrenia. Schizophrenia Research 53, 83-91.

Vestergaard, M., Mork, A., Madsen, K.M., Olsen, J., 2005. Paternal age and epilepsy in the offspring. European Journal of Epidemiology 20, 1003-1005.

Weiser, M., Reichenberg, A., Werbeloff, N., Kleinhaus, K., Lubin, G., Shmushkevitch, M., Caspi, A., Malaspina, D., Davidson, M., 2008. Advanced Paternal age at birth is associated with poorer social functioning in adolescent males: shedding light in a core symptom of schizophrenia and autism. Schizophrenia Bulletin 34, 1042-1046.

Wu, Y., Liu, X., Luo, H., Deng, W., Zhao, G., Wang, Q., Zhang, L., Ma, X., Liu, X., Murray, R.A., Collier, D.A., Li, T., 2012. Advanced paternal age increases the risk of schizophrenia and obsessivecompulsive disorder in a Chinese Han population. Psychiatry Research 198, 353-359.

Xu, B., Ionita-Laza, I., Roos, J.L., Boone, B., Woodrick, S., Sun, Y., Levy, S., Gogos, J.A., Karayiorgou, M., 2012. De novo gene mutations highlight patterns of genetic and neural complexity in schizophrenia. Nature Genetics 44, 1365-1369. 


\section{APPENDIX A: Questionnaire used to probe for early non-psychotic deviant}

behaviour:

1. How did you get along with other children? Did you have friends? Did you enjoy playing with other children? (IF SUBJECT INDICATES ISOLATION OR PROBLEMS). What problems did you have? When (at what age) did these difficulties begin?

2. As a child before age 10, did you do things that you or others thought were odd or unusual? (IF YES) What were they? When (at what age) did this begin? 3. Were you aggressive as a child, compared to others? (IF YES) Did you have any problems related to this? Could you describe the problems to me? Did anyone ever comment on this? (IF YES) When (at what age) did these problems begin?

4. Did you have a lot of fears before the age of 10 ? Do you think you had more fears than other children? (IF YES) Why do you say that? What were you afraid of? (IF FEARS ARE REPORTED) When (at what age) did these fears begin?

5. Did you ever go through periods of extreme sadness? (IF YES) More so than other children? Could you describe this? When (at what age) did this begin?

6 . Did you have any problems with attention or daydreaming before the age of 10 ? (IF YES) Could you describe the problems? Did anyone else notice and comment on this? Did you have problems in school because of attention? When (at what age) did you or others notice the problems?

7. As a child before age 10, were you ever diagnosed with a learning disability or did you have trouble completing schoolwork? (IF YES) What kind of problems did you have e.g. reading delay, speech impediment, and poor concentration? Were you ever placed in a special class or were you ever given special tutoring to help with your schoolwork? (IF YES) Could you describe the kind of help you received? When (at what age) did these problems begin? 